\title{
EFEITO DA ÉPOCA DE APLICAÇÃO DE FUNGICIDA NO CONTROLE DE DOENÇAS FOLIARES NA CULTURA DO MILHO SAFRINHA
}

Pedro Augusto Bosquii ; Thais de Oliveira lácono Ramari²; Cleiltan Novais da Silva3; Edison Schmdit Filho ${ }^{4}$; Francielli Gasparotto ${ }^{5}$

${ }^{1}$ Acadêmico do curso de Agronomia/Centro Universitário de Maringá Unicesumar, campus Maringá - PR, Brasil.

${ }^{2}$ Professora Mestre do Departamento de Agronomia/Centro Universitário de Maringá - Unicesumar, campus Maringá - PR, Brasil.

${ }^{3}$ Pós-doutoranda do programa de Pós-graduação em Tecnologias Limpas do

Centro Universitário de Maringá, Unicesumar - Maringá - PR, Brasil.

${ }^{4}$ Professor Doutor do Programa de Mestrado em Tecnologias Limpas e do Departamento de Agronomia/ Centro Universitário de Maringá - Unicesumar, campus Maringá - PR, Brasil. Pesquisador do Instituto Cesumar de Ciência, Tecnologia e Inovação (ICETI).

${ }^{5}$ Professora Doutora do Programa de Mestrado em Tecnologias Limpas e do Departamento de Agronomia/ Centro Universitário de Maringá - Unicesumar, campus Maringá - PR, Brasil. Pesquisadora do Instituto Cesumar de Ciência,

Tecnologia e Inovação (francielli.gasparotto@unicesumar.edu.br)

Recebido em: 06/04/2018 - Aprovado em: 10/06/2018 - Publicado em: 20/06/2018 DOI: 10.18677/EnciBio_2018A39

\begin{abstract}
A época adequada de aplicação de fungicida interfere diretamente nos custos de produção, na produtividade e no meio ambiente. Assim, o presente trabalho objetivou avaliar a época ideal e os custos de aplicação de fungicida na cultura de milho safrinha para controle de doenças foliares. O delineamento experimental foi em blocos casualizados com oito tratamentos, representando diferentes épocas de aplicação do fungicida piraclostrobina + fluxapiroxade, distribuídos entre os estádios V8 (vegetativo com oitos folhas); PP (pré-pendoamento) e 20PP (20 dias após prépendoamento) e seis repetições por tratamento, em que; T1= (aplicação em V8 + PP + 20PP); T2 (aplicação em V8 + PP); T3 (aplicação em V8); T4 (aplicação em PP + 20PP); T5 (aplicação em PP); T6 (Testemunha - sem aplicação); T7 (monitoramento); T8 (aplicação em 20PP). Ao final do ciclo da cultura foi quantificada a produtividade e de acordo com os custos de cada tratamento estabeleceu-se a rentabilidade econômica/tratamento. Quanto à sanidade da cultura, todos os tratamentos em que foi aplicado o fungicida, independente da época e quantidade de aplicações diferiram significativamente da testemunha. Os tratamentos T1, T2, T3, T4 e T5 apresentaram maiores produtividades. Nas condições deste experimento a aplicação do fungicida piraclostrobina (333 g. $\left.\mathrm{L}^{-1}\right)+$ fluxapiroxade (167 g.. $\mathrm{L}^{-1}$ ) em pré-pendoamento (T5) foi a que apresentou melhor custo benefício para o controle de doenças foliares na cultura do milho.
\end{abstract}

PALAVRAS-CHAVE: Controle químico, fitossanidade, impacto ambiental, Zea mays. 


\title{
EFFECT OF THE FUNGICID APPLICATION TIME ON THE CONTROL OF DISEASES IN THE WINTER CORN CROPS.
}

\begin{abstract}
Proper timing of fungicide application directly interferes with production costs, productivity and the environment. Thus, the present work aimed to evaluate the ideal time and costs of fungicide application in the corn crop for control of foliar diseases. The experimental design was randomized blocks with eight treatments, representing different times of application of fungicide pyraclostrobin + fluxapiroxade, distributed between V8 stages (vegetative with eight leaves); PP (pre-tasseling) and 20PP (20 days post pre-tasseling) and six replicates per treatment, wherein; $\mathrm{T} 1=$ (application in V8 + PP + 20PP); T2 (application in V8 + PP); T3 (V8 application); T4 (application in PP + 20PP); T5 (application in PP); T6 (control - no application); T7 (monitoring); T8 (application in 20PP). At the end of the crop cycle the productivity was quantified and according to the costs of each treatment the economic profitability / treatment was established. Regarding the health of the crop, all treatments in which the fungicide was applied, regardless of season and amount of application differed significantly from the control. The treatments T1, T2, T3, T4 and T5 presented higher productivities. Under the conditions of this experiment, the application of the fungicide pyraclostrobin (333 g.L-1) + fluxapiroxade (167 g.L-1) in pre-tasseling (T5) was the one that presented the best cost benefit for the control of foliar diseases in growing corn.
\end{abstract}

KEYWORDS: Chemical control, phytosanitary, environmental impact, Zea mays.

\section{INTRODUÇÃO}

O milho (Zea mays L.) pertence à família Poaceae, cujos grãos têm grande importância econômica e social. O Brasil ocupa a terceira posição entre os principais produtores mundiais de milho, atrás dos Estados Unidos e China. A produção de milho no Brasil foi aproximadamente 97,19 milhões de toneladas, distribuídas entre a primeira safra (30,5 milhões de toneladas) e a segunda safra $(66,6$ milhões de toneladas) (CONAB, 2017).

Ainda segundo a CONAB (2017) o milho é cultivado em praticamente todo o território nacional e a produção em duas safras anuais diferencia o País dos principais produtores internacionais, sendo a região Centro-Sul do País responsável por $83,9 \%$ da produção nacional de milho e o cultivo da segunda safra ou 'safrinha' ocorre predominantemente nesta região, sendo os principais produtores os estados do Paraná, Minas Gerais, São Paulo, Goiás, Mato Grosso do Sul e Mato Grosso.

Embora a segunda safra de milho proporcione vantagens econômicas aos agricultores e ao País, esse sistema de cultivo ocasiona implicações na sanidade das lavouras, favorecendo o aumento de danos causados por doenças. Pereira et al. (2005) reforçam ainda que plantios antecipados, sob irrigação, plantios da safra de verão e o aumento do plantio safrinha são responsáveis pela continuidade temporal da cultura de milho, proporcionando a cada ano o surgimento de novos problemas para a cultura, principalmente em relação às doenças.

Neste contexto, as doenças foliares que antes apresentavam baixa incidência, com o passar dos anos estão provocando maiores danos (COTA, 2014). Dentre as principais doenças fúngicas foliares associadas à cultura do milho no Brasil, destacam-se a mancha-branca (Phaeosphaeria maydis), Helmintosporiose (Exserohilum turcicum), mancha de macrospora (Stenocarpella macrospora) e a cercosporiose causada por Cercospora zeae-maydis (MANFROI et al., 2016), além 
da ferrugem polissora, cujo agente etiológico é a Puccinia polysora, sendo uma das mais relevantes doenças do milho do País (COLOMBO et al., 2014).

A mancha foliar de Phaeosphaeria ou mancha-branca vem se destacando entre as doenças foliares na cultura do milho nos últimos anos, devido principalmente à sua grande amplitude geográfica de ocorrência (MANFROI et al., 2016). O agente causal da mancha branca do milho foi identificado por Rane et al. em 1965, na Índia, como sendo o fungo Phaeosphaeria maydis, porém, existem controvérsias sobre o agente etiológico da mancha branca do milho no Brasil (COSTA t al., 2012), em que pesquisas apontaram que o provável agente causal desta doença é a bactéria Pantoea ananatis, a qual favorece o estabelecimento do fungo P. maydis (PACCOLA-MEIRELLES et al., 2001). Porém, independente da definição de qual o agente causal desta enfermidade, de acordo com Brito et al. (2013) híbridos de milho susceptíveis à mancha-branca podem apresentar perdas de até $60 \%$ na produção.

Outra doença com expressiva significância na cultura do milho é a cercosporiose, pois as manchas características da doença evoluem rapidamente destruindo grande parte da área foliar (NEGA et al., 2016). Da mesma forma, a Helmintosporiose, cujo agente causal Exserohilum turcicum, vem sendo largamente disseminada em cultivos de milho por todo o País (PEREIRA et al., 2005), podendo resultar em incidência de $100 \%$ em áreas de cultivo, provocando reduções significativas do rendimento da cultura (RAMATHANI et al., 2011).

Geralmente, o manejo das doenças na cultura do milho é realizado, principalmente, mediante o uso de cultivares resistentes, atrelado às medidas culturais (LANZA et al., 2016), mas para alcançar o máximo de produtividade que a cultura pode expressar é necessária associá-la a outras formas de manejo, sendo o controle químico um dos mais utilizados pelos produtores.

A pressão de doenças fúngicas que podem afetar a cultura do milho é extremamente alta em função do aumento de inóculo inicial nas áreas cultivadas. Assim, o controle químico com o uso de fungicidas vem sendo empregado para mitigar os danos, mas muitas vezes é realizado de forma inadequada, aumentando a pressão de seleção sobre os patógenos e induzindo a resistência destes agentes causais (COSTA ;COTA, 2009).

Até o final da década de 90, não havia registro, no Ministério da Agricultura, Pecuária e Abastecimento, de fungicidas para o controle de doenças foliares na cultura do milho (COSTA ; COTA, 2009), atualmente, segundo a Agência de Defesa Agropecuária do Paraná- ADAPAR (2017) existem 75 produtos comerciais liberados para o estado do Paraná, mostrando o crescimento do mercado de fungicidas para essa cultura.

Neste sentido, são muitos os trabalhos realizados que comprovam a eficiência e a viabilidade do uso de fungicidas na cultura do milho (COSTA et al., 2012; SILVA et al., 2016; ROSA et al., 2017). Porém, poucos abordam os fatores que influenciam a aplicação destes produtos, como a melhor época de aplicação. Pois a determinação do time de aplicação é importante na definição da melhor época de aplicação de fungicidas, visando maximizar a produtividade e diminuir os impactos negativos para o meio ambiente. Assim, objetivou-se com este trabalho avaliar a época ideal e os custos de aplicação de fungicida na cultura de milho safrinha para controle de doenças foliares. 


\section{MATERIAL E MÉTODOS}

O experimento foi realizado entre os meses de março a agosto de 2017, em uma propriedade no município de São Jorge do Ivaí, estado do Paraná $\left(23^{\circ} 25^{\prime} 58^{\prime \prime}\right.$ $S 52^{\circ} 17^{\prime} 34^{\prime \prime}$ O) com altitude de $600 \mathrm{~m}$ e clima subtropical úmido mesotérmico. A unidade experimental foi locada em área anteriormente cultivada, na safra de inverno, com milho e na de verão, do ano anterior, com a cultura da soja. O hibrido utilizado no experimento foi o Fórmula Viptera, Syngenta@ ${ }^{\circledR}$, que apresenta resistência moderada a Puccinia sorghi, Diplodia maydis e Diplodia macrospora, sendo moderadamente suscetível a Puccinia polissora e suscetível a Phaeosphaeria maydis, Exserohilum turcicum e Cercospora zeae-maydis.

O delineamento experimental foi de blocos ao acaso, com 8 tratamentos e 6 repetições, totalizando 48 unidades experimentais. Os tratamentos consistiram em uma variação de épocas de aplicação de fungicida em diferentes estádio fenológicos da planta, a saber: V8 (estádio fenológico com 8 folhas); PP (pré-pendoamento); 20PP (20 dias após a aplicação no pré-pendoamento) e após a detecção da ocorrência de doenças na área (monitoramento). Em que os tratamentos foram: T1= (aplicação em V8 + PP + 20PP); T2 (aplicação em V8 + PP); T3 (aplicação em V8); T4 (aplicação em PP + 20PP); T5 (aplicação em PP); T6 (Testemunha - sem aplicação); T7 (monitoramento); T8 (aplicação em 20PP).

Cada tratamento foi constituído de seis fileiras com espaçamento de 0,9 metros entre fileiras e 11 metros de comprimento, separados por corredores de 1 metro de largura entre os blocos. A cultura recebeu os tratos culturais iguais aos manejados no restante da propriedade para que as condições se assemelhassem ao máximo a de uma lavoura da região, exceto na aplicação do fungicida, que seguiu o cronograma estabelecido de acordo com os tratamentos.

O fungicida utilizado correspondeu a mistura comercial registrada para uso na cultura do milho piraclostrobina (333 g. $\left.\mathrm{L}^{-1}\right)+$ fluxapiroxade $\left(167 \mathrm{~g} \cdot \mathrm{L}^{-1}\right)$, na dose de $350 \mathrm{ml}$ de produto comercial por hectare com adição de $1 \%$ de óleo mineral na calda. As aplicações foram realizadas com um pulverizador costal de precisão com tanque de $\mathrm{CO}_{2}$ acoplado a uma garrafa 2 litros como reservatório, e uma barra com 4 bicos aspersores tipo leque $0,2 \mathrm{~mL}$. A calibração do equipamento foi realizada cronometrando o tempo para percorrer cinquenta metros, e utilizando um copo calibrador para aferir a pressão do equipamento.

A cultura foi monitorada semanalmente e as avaliações de incidência (número de plantas sintomáticas) e severidade (porcentagem de área foliar com sintomas de cada doença nas folhas acima e abaixo da espiga) das doenças incidentes naturalmente na área foram determinadas visualmente aos 103, 110 e aos 117 dias após o plantio, totalizando três avaliações.

Ao final do ciclo da cultura avaliou-se a produtividade em cada tratamento, por meio da colheita de seis metros lineares de cada uma das duas linhas centrais de cada parcela, para se evitar qualquer tipo de interferência, como falhas na germinação ou plantas atacadas por afídeos. Realizou-se a debulha em uma trilhadeira e então as amostras de cada tratamento foram pesadas em uma balança de precisão. Com base nos resultados de produtividade realizou-se o cálculo do retorno econômico $(\mathrm{R})$ de acordo com a Equação 1 proposta por Donato e Bonato (2013).

$$
R=((\text { Ptrat }- \text { Ptest }) \times M)-C
$$


em que,

$\mathrm{P}$ trat $=$ produtividade de cada tratamento com aplicação de fungicida, sc.ha ${ }^{-1}$;

$\mathrm{P}$ test $=$ produtividade da testemunha, $\mathrm{sc} \cdot \mathrm{ha}^{-1}$;

$\mathrm{M}=$ preço da saca do milho;

$\mathrm{C}=$ custo do tratamento com fungicida

As informações obtidas para estabelecimento do custo foram obtidas de uma cooperativa da região, em que o preço do litro de fungicida e do óleo aplicado foi de $R \$ 220,00$ e $R \$ 18,00$, respectivamente, e o preço da saca de milho foi de $R \$ 27,00$. Os resultados de incidência e severidade das doenças foram utilizados para estabelecer curvas temporais de progresso das doenças para cada tratamento. Os resultados foram tratados estatisticamente e as médias comparadas pelo teste Scott-Knott com nível de 5\% de significância.

\section{RESULTADOS E DISCUSSÃO}

As doenças foliares que ocorreram na cultura do milho durante o período da avaliação foram mancha branca, cercospora, helmintosporiose e ferrugem polissora, sendo a última com menor severidade.A ferrugem polissora ocorreu apenas no tratamento 1 (aplicação em estádio $\mathrm{V} 8+$ pré pendoamento +20 após pré pendoamento) com severidade inferior a $1 \%$, porém devido a baixa severidade não houveram diferenças significativas entre os demais tratamentos avaliados (Figura 1A).

Este fato pode estar relacionado às características do híbrido empregado no experimento, descrito como moderadamente susceptível a ferrugem polissora. $\mathrm{O}$ emprego de híbridos resistentes a patógeno é indicado como a ferramenta mais econômica e eficiente no manejo integrado de doenças na cultura do milho (COLOMBO et al., 2014). Atrelado ao nível de resistência do híbrido, as condições climáticas podem não ter sido favoráveis à propagação do inóculo desse patógeno.
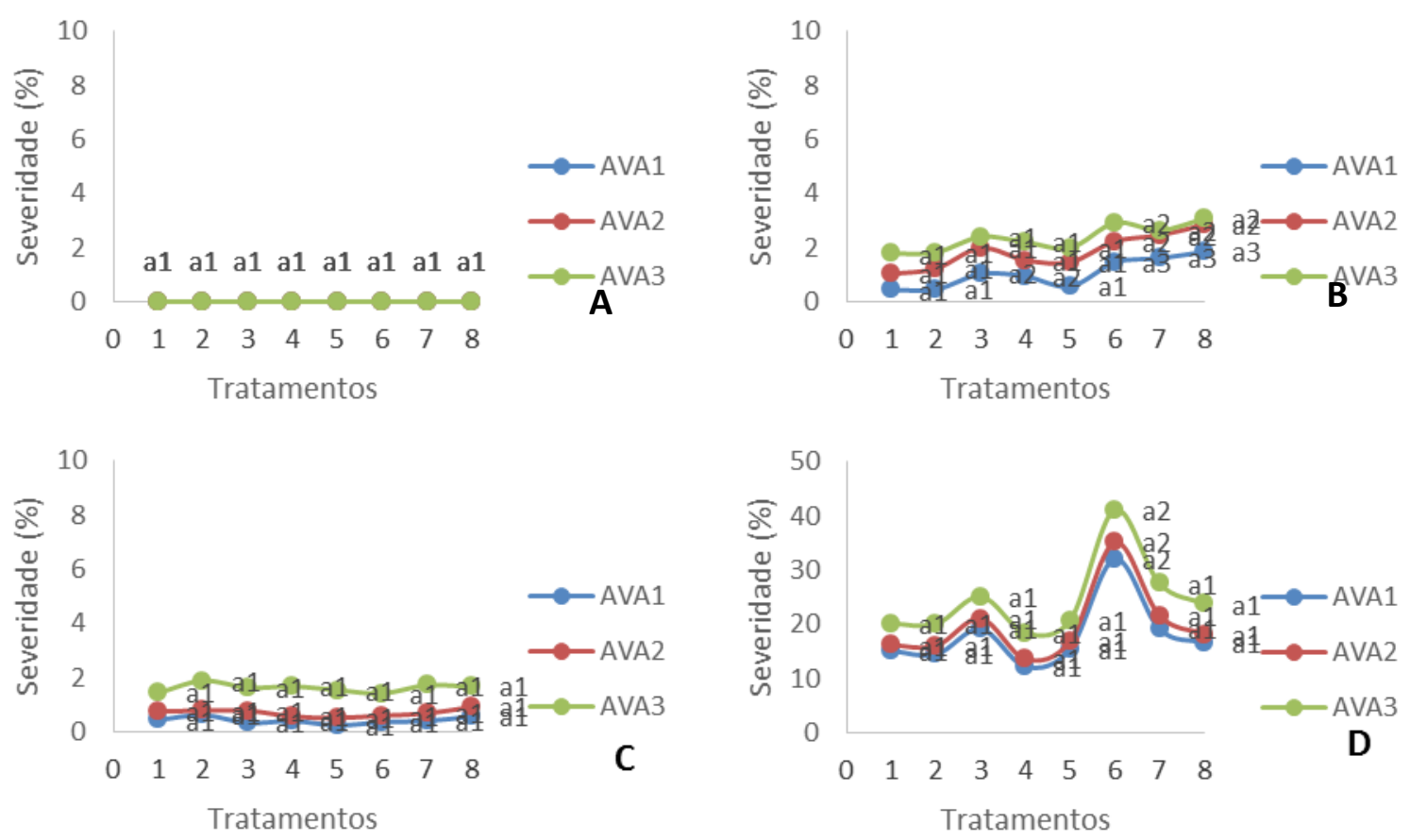

FIGURA 1. Severidade de ferrugem polissora (A), cercosporiose (B), helmintosporiose (C) e mancha branca (D) na cultura do milho em diferentes épocas de aplicação de fungicida. Tratamentos: 1 (V8 + PP + 20PP) 2 (V8 + PP); 3 (V8); 4 (PP + 20PP); 5 (PP); 6(testemunha); 7 (monitoramento-20 PP); 8 (20PP). ${ }^{2}$ Letras minúsculas com números diferentes representam as diferenças estatísticas. ${ }^{3} A V A 1$; AVA2 e AVA3, representam respectivamente as avaliações após 103, 110 e 117 dias do plantio. 
Da mesma forma, a severidade de cercosporiose na área também foi baixa (Figura1B), porém ocorreram diferenças estatísticas entre os tratamentos. Sendo que, independente da época de avaliação os tratamentos com menores severidades foram aplicações de fungicidas em V8 + pré pendoamento +20 dias após o pré pendoamento (T1); V8 + pré pendoamento (T2) e aplicações apenas no pré pendoamento (T5), com severidade de $0,44 \%, 0,46 \%$ e $0,57 \%$, respectivamente, diferindo estatisticamente da testemunha (T6), na qual a severidade alcançou $1,46 \%$. Jardine e Laca-Buendia (2009) estudando fungicidas para o controle da cercosporiose em milho observaram severidades maiores, atingindo $34,79 \%$, onde o fungicida mais eficiente foi à mistura epoxiconazole + piraclostrobina aplicado no estádio R6.

Para a helmintosporiose a incidência ocorreu em todos os tratamentos com severidade máxima de $2 \%$ na terceira avaliação. No entanto, não foram observadas diferenças significativas entre os tratamentos representados pelas épocas de aplicação (Figura 1C).

Dentre às doenças incidentes na cultura, a mancha branca foi a que apresentou os maiores valores de severidade. No tratamento 6 (testemunha) verificou-se $41,17 \%$ de área foliar afetada (Figura 1D), demonstrando que essa doença pode ser muito agressiva se não manejada corretamente, principalmente em híbridos suscetíveis e condições climáticas favoráveis ao estabelecimento da doença.

Na Figura 1D verifica-se que a mancha-branca atingiu os maiores índices de severidade na terceira avaliação, coincidindo com o estágio mais avançado de desenvolvimento da cultura. Independente da época de avaliação todos os tratamentos diferiram da testemunha (T6), ou seja, a aplicação do fungicida piraclostrobina + fluxapiroxade foi eficiente no controle da mancha branca nos diferentes estádios fenológicos avaliado neste estudo.

Corroborando estes resultados Costa et al. (2012) avaliando híbridos de milho com diferentes níveis de resistência e suscetibilidade a mancha-branca com aplicações de diferentes grupos químicos de fungicidas verificaram que os fungicidas do grupo das estrobilurinas foram os que apresentaram maior eficiência no controle da doença. Os autores ainda recomendaram a utilização de fungicidas para os cultivares que apresentam suscetibilidade à doença.

$\mathrm{Na}$ tabela 1 são apresentadas as médias referentes à análise conjunta de todas as doenças foliares avaliadas neste estudo, distribuídas entre as três avaliações. Todos os tratamentos em que foi aplicado o fungicida piraclostrobina + fluxapiroxade, independente da época de aplicação, diferenciaram estatisticamente da testemunha. Este resultado corrobora com os demais resultados deste trabalho visto que T6 (testemunha) é o único tratamento em que o controle químico não foi utilizado.

Cabe ressaltar, que a frequência ou não de determinadas doenças está intimamente ligada com fatores relacionados ao manejo da cultura do milho. Fatores como plantio em época adequada, evitando períodos com condições ambientais favoráveis ao desenvolvimento do patógeno, utilização de sementes de boa qualidade, uso de rotação com culturas não suscetíveis, adubação adequada e colheita na época correta (JUNIOR et al., 2015), podem minimizar a ocorrência de doenças e consequentemente, a utilização de fungicidas. 
TABELA 1. Severidade de doenças foliares $(\%)$ e produtividade média $\left(\mathrm{kg} / \mathrm{ha}^{-1}\right)$ de milho sob controle químico com o fungicida piraclostrobina $\left(333 \mathrm{~g} \cdot \mathrm{L}^{-1}\right)+$ fluxapiroxade (167 g.L-1), em diferentes épocas de aplicação em três avaliações.

\begin{tabular}{lccc}
\hline Tratamentos $^{1}$ & \multicolumn{3}{c}{ Severidade (\%) } \\
\cline { 2 - 4 } & AV1 $^{\mathbf{2}}$ & AV2 & AV3 \\
\hline T1 & $16,04 \mathrm{a}$ & $17,99 \mathrm{a}$ & $23,42 \mathrm{a}$ \\
T2 & $15,56 \mathrm{a}$ & $18,07 \mathrm{a}$ & $23,81 \mathrm{a}$ \\
T3 & $20,54 \mathrm{a}$ & $23,86 \mathrm{a}$ & $29,21 \mathrm{a}$ \\
T4 & $13,57 \mathrm{a}$ & $15,70 \mathrm{a}$ & $22,31 \mathrm{a}$ \\
T5 & $16,26 \mathrm{a}$ & $18,94 \mathrm{a}$ & $24,22 \mathrm{a}$ \\
T6 & $33,93 \mathrm{~b}$ & $38,01 \mathrm{~b}$ & $45,50 \mathrm{~b}$ \\
T7 & $21,12 \mathrm{a}$ & $24,75 \mathrm{a}$ & $31,90 \mathrm{a}$ \\
T8 & $19,01 \mathrm{a}$ & $22,54 \mathrm{a}$ & $28,51 \mathrm{a}$ \\
\hline
\end{tabular}

${ }^{1}$ Tratamentos: T1 - V8 (estádio fenológico com 8 folhas) + PP (pré-pendoamento) + 20PP (20 dias após a aplicação no pré-pendoamento); T2 - V8 + PP; T3 - V8; T4 - PP + 20PP; T5 - PP; T6- Testemunha (sem aplicação); T7 - Monitoramento (20 PP); T8 - 20PP.

${ }^{2}$ Avaliações: AVA1 - 103 dias após o plantio; AVA2 - 110 dias após o plantio; AVA3 - 117 dias após o plantio. *Letras diferentes nas colunas representam diferenças significativas a $5 \%$ de probabilidade.

Desse modo, o manejo além de reduzir os custos de produção ainda contribui para mitigação dos danos ao meio ambiente. Destaca-se ainda que a ocorrência de patógenos na cultura do milho depende do ambiente e consequentemente da região de cultivo (COSTA ;COTA, 2009).

Quanto à produtividade, foi observada uma variação entre 86 a $97 \mathrm{sc}^{-h^{-1}}{ }^{-1}$ em que aplicações nos tratamentos de 01 a 05 alcançaram maiores índices de produtividade diferindo significativamente da testemunha e dos tratamentos onde realizou-se apenas uma aplicação 20 dias após o pré pendoamento (Tabela 2).

TABELA 2. Dados médios de produtividade $(P)$, incremento de produtividade (IP), receita $(R)$, custo $(C)$ e retorno econômico (RE) da aplicação em diferentes épocas do fungicida piraclostrobina $\left(333 \mathrm{~g} \cdot \mathrm{L}^{-1}\right)+$ fluxapiroxade (167 g.L-1 $)$ em na cultura do milho safrinha no município de São Jorge do Ivaí - PR, 2017.

\begin{tabular}{|c|c|c|c|c|c|}
\hline Tratamentos $^{1}$ & $\begin{array}{c}P \\
\mathrm{~kg} \mathrm{ha}^{-1}\end{array}$ & $\begin{array}{c}\text { IP } \\
\text { sc ha }{ }^{-1}\end{array}$ & $\begin{array}{c}\mathbf{R}^{2} \\
\mathbf{R} \boldsymbol{\$} \mathbf{~ h a}^{-1}\end{array}$ & $\begin{array}{c}\mathbf{C}^{3} \\
\mathbf{R} \$ \mathbf{h a}^{-1}\end{array}$ & $\begin{array}{c}\mathbf{R E} \\
\mathbf{R} \$ \mathrm{ha}^{-1}\end{array}$ \\
\hline T1 & $95,85 \mathrm{~b}$ & 9,09 & 245,43 & 312,00 & $-66,57$ \\
\hline T2 & $97,12 \mathrm{~b}$ & 10,36 & 279,72 & 208,00 & 71,72 \\
\hline T3 & $94,43 \mathrm{~b}$ & 7,67 & 207,09 & 104,00 & 103,09 \\
\hline T4 & $97,23 \mathrm{~b}$ & 10,47 & 282,69 & 208,00 & 74,69 \\
\hline T5 & $95,23 \mathrm{~b}$ & 8,47 & 228,69 & 104,00 & 124,69 \\
\hline T6 & $86,76 \mathrm{a}$ & 0,00 & 0,00 & 0,00 & 0,00 \\
\hline T7 & $90,21 \mathrm{a}$ & 3,45 & 93,15 & 104,00 & $-10,85$ \\
\hline T8 & 89,93 a & 3,17 & 85,59 & 104,00 & $-18,41$ \\
\hline
\end{tabular}

'Tratamentos: T1 - V8 (estádio fenológico com 8 folhas) + PP (pré-pendoamento) + 20PP (20 dias após a aplicação no pré-pendoamento); T2 - V8 + PP; T3 - V8; T4 - PP + 20PP; T5 - PP; T6Testemunha (sem aplicação); T7 - Monitoramento (20 PP); T8 - 20PP.

${ }^{2}$ Preço da saca de milho - $\mathrm{R} \$ 27,00$.

${ }^{3}$ Custo por aplicação - R\$ 104,00 ha-1 (fungicida + óleo + aplicação). 
No trabalho de Uebel (2015) o híbrido Formula apresentou as maiores porcentagens de incremento de produtividade de grãos pela utilização de fungicidas do grupo das carboxamidas no controle de doenças, sendo que o incremento de produtividade variou de $24,2 \%$ a $47 \%$, incrementos maiores do que os obtidos neste trabalho, o que comprova a resposta do hibrido ao controle químico de doenças foliares.

No entanto, Vilela et al. (2012) verificaram que a aplicação dos fungicidas piraclostrobina + epoxiconazol e azoxistrobina + ciproconazol no pré-pendoamento do milho reduziu a incidência de doenças foliares; porém, não foi suficiente para propiciar incremento de produtividade da cultura. Esses resultados corroboram com os encontrados por Moratelli et al. (2015) em experimentos com aplicação da mistura de triazol + estrobirulina para controle de ferrugem e cercospora, onde os autores concluíram que a aplicação dos fungicidas foi viável para o manejo da severidade destas doenças no milho, embora não foi observada diferença na produtividade.

Na tabela 2 pode-se verificar que os tratamentos T1, T7 e T8 tiveram resultados negativos, ou seja, o valor investido foi maior do que o retorno da cultura. Os tratamentos com maiores retornos econômicos foram o T5 e o T3, com R\$ $124,69 \mathrm{ha}^{-1}$ e 103,09 ha-1 respectivamente, diferindo em $\mathrm{R} \$ 49,95 \mathrm{ha}^{-1}$ e $\mathrm{R} \$ 28,40 \mathrm{ha}^{-}$ ${ }^{1}$ do tratamento 4 , que foi o terceiro com maior retorno.

Assim, nas condições deste experimento, a aplicação do fungicida em prépendoamento (T5) foi a que apresentou melhor custo benefício para o controle de doenças foliares no milho. Estes dados corroboram parcialmente com os descritos por Rezende et al. (2017), em experimentos com aplicação de diferentes fungicidas em milho no estádio de pré-pendoamento para controle de cercosporiose e helmintosporiose em que o tratamento com azoxistrobina + ciproconazole apresentou a maior produtividade, gerando maiores lucratividades com retorno econômico.

Resultados semelhantes foram encontrados por Oliveira et al. (2011), em que aplicações dos fungicidas azoxistrobina + ciproconazole em pré pendoamento e 15 dias após o pré pendoamento apresentaram maiores produtividade na cultura do milho. Os autores observaram ainda o efeito significativo entre épocas de aplicação e o principio ativo dos fungicidas.

Bussolaro et al. (2009), avaliaram a eficácia de fungicidas para o controle de doenças, em diferentes estádios da cultura do milho e mencionaram que a utilização de fungicidas (epoxiconazole + piraclostrobina e azoxistrobina + ciproconazol) proporcionou um acréscimo na produção, mesmo quando aplicados em diferentes épocas. Ressalta-se que cada híbrido, fungicida e região apresentam suas particularidades no desenvolvimento de doenças fúngicas em milho, sendo necessário observar tais condições e adaptá-las para tal realidade.

\section{CONCLUSÃO} branca.

A doença foliar com maior severidade na cultura do milho foi a mancha-

Com exceção da testemunha (T6) os demais tratamentos não apresentaram diferenças em relação às épocas de aplicação do fungicida em nenhuma das três avaliações.

A aplicação do fungicida piraclostrobina + fluxapiroxade em pré-pendoamento (T5) obteve o melhor custo-benefício para o controle de doenças foliares na cultura do milho, pois apresentou maior retorno econômico. 


\section{REFERÊNCIAS}

ADAPAR- Agência de defesa agropecuária do Paraná (2017). Disponível em: http://celepar07web.pr.gov.br/agrotoxicos/pesquisar.asp >

BRITO, A. H.; PINHO, R. G. V.; PEREIRA, J. L. A. R.; BALESTRE, M. Controle químico da Cercosporiose, Mancha-Branca e dos Grãos Ardidos em milho. Revista Ceres, v. 60, n. 5, p. 629-635, 2013. Disponível em: $<$ http://www.scielo.br/scielo.php?script=sci_arttext\&pid=S0034-

737X2013000500005\&lng=en\&nrm=iso>.

BUSSOLARO, A.; ABREU, L. ; FONSECA, F. J. Eficiência de fungicidas aplicados em diferentes estádios de desenvolvimento na cultura do milho (Zea mays) no oeste de SC. In: Ciência no Brasil: Anais XIII Seminário de Iniciação Cientifica, VI Seminario de Pesquisa, IV Seminário de Extensão e II Seminário de Ensino, 2009, Chapeco-SC.

COLOMBO, G. A.; VAZ-DE-MELO, A.; TAUBINGER, M.; TAVARES, R. D. C.; SILVA, R. R. D. Análise dialélica para resistência a ferrugem polissora em milho em diferentes níveis de adubação fosfatada. Bragantia, v. 73, n. 1, p. 65-71, 2014. http://www.scielo.br/pdf/brag/2014nahead/aop_bragantia_afs0050.pdf>. DOI: http://dx.doi.org/10.15090/brag.2014.002.

CONAB - Companhia Nacional de Abastecimento. $1^{\circ}$ Levantamento - Safra 2016/2017 - Grãos. Brasília: Conab, 2017. Disponível em: < http://www.conab.gov.br/OlalaCMS/uploads/arquivos/17_09_12_10_14_36_boletim_ graos_setembro_2017.pdf >.

COSTA, R. V.; COTA, L. V. Controle químico de doenças na cultura do milho: aspectos a serem considerados na tomada de decisão sobre aplicação. Sete Lagoas: Embrapa Milho e Sorgo, 2009. 11 p. (Embrapa Milho e Sorgo. Circular técnica, 125).

COSTA, R. V.; COTA, L. V.; SILVA, D. D.; LANZA, F. E.; FIGUEIREDO, J. E. F. Eficiência de fungicidas para o controle da mancha branca do milho. Revista Brasileira de Milho e Sorgo, v.11, n.3, p. 291-301, 2012. Disponível em: http://rbms.cnpms.embrapa.br/index.php/ojs/article/view/384 >

COTA, L. V. Manejo integrado de doenças na cultura do milho. Panorama Fitossanitário: cultura do milho. 2014. Disponível em: http://panorama.cnpms.embrapa.br/controle >.

DONATO, F. V.; BONALDO, S. M. Avaliação de diferentes fungicidas no controle de doenças foliares no milho na região norte de Mato Grosso. Enciclopédia Biosfera, v. 9 , n. $17 ; \quad$ p. 375-384, 2013. Disponível em: $<$ file://CC:/Users/francielli.gasparott/Downloads/AVALIACAO\%20DE \%20DIFERENTES.pdf>.

JARDINE, D. F.; LACA-BUENDIA, J. P. Eficiência de fungicidas no controle de doenças foliares na cultura do milho. FAZU em Revista, n. 6, p. 11-52, 2009. 
Disponível

em:

http://www.fazu.br/ojs/index.php/fazuemrevista/article/viewArticle/13 >

JUNIOR, M. R. R.; GERICÓ, T. G. CANAVER, A. B. RODRIGUES, A. B. Levantamento de doenças na cultura do milho (Zea mays) cultivado após sucessivos anos de plantio de pastagem na região de Marília-SP. Unimar Ciências, v. 24, n. 12, 2015. Disponível em: http://ojs.unimar.br/index.php/ciencias/article/view/464.

LANZA, F. E.; ZAMBOLIM, L.; COSTA, R. V.; SILVA, D. D.; QUEIROZ, V. A. V. et al., Aplicação foliar de fungicidas e incidência de grãos ardidos e fumonisinas totais em milho. Pesquisa Agropecuária Brasileira, v. 51, n. 5, p. 638-646, 2016. Disponivel em: https://dx.doi.org/10.1590/S0100-204X2016000500026. DOI: 10.1590/S0100-204X2016000500026

MANFROI, E.; LANGHINOTTI, C.; DANELLI, A.; PARIZE, G. Controle químico de doenças foliares e rendimento de grãos na cultura do milho. Revista Brasileira de Milho e Sorgo, v.15, n.2, p.357-365, 2016. Disponível em: http://dx.doi.org/10.18512/1980-6477/rbms.v15n2p357-365.> DOI: 10.18512/19806477/rbms.v15n2p357-365.

MORATELLI, G.; KAEFER, K. A. C.; ERTEL, F.; VOGT, R. T.; FERREIRA, S. D.; EGEWARTH,V. A.; et al.,; Effect of fungicide application times in the control management of leaf foliar diseases in maize. African Journal of Agricultural Research, v. 10, n. 38, p. 3686-3695, 2015. Disponível em: <https://doi.org/10.5897/AJAR2015.9984>. DOI: 10.5897/AJAR2015.9984

NEGA, A.; LEMESSA, F.; BERECHA, G. Distribution and Importance of Maize Grey Leaf Spot Cercospora zeae-maydis (Tehon and Daniels) in South and Southwest Ethiopia. Journal of Plant Pathology \& Microbiology, v. 7, n. 7, 362, 2016. Disponivel em: <https://www.omicsonline.org/open-access/distribution-andimportance-of-maize-grey-leaf-spot-cercospora-zeaemaydistehon-and-daniels-insouth-and-southwest-ethiopia-2157-7471-1000362. php?aid=77102\#11>. DOI: 10.4172/2157- 7471.1000362.

OLIVEIRA, V. M.; SOUSA, L. B.; BISINOTTO, F. F.; SANTOS, F. M. Produtividade de milho em função de diferentes aplicações de fungicidas. Enciclopédia Biosfera, v.7, n.12, p.1-6. 2011. Disponível em: < http://www.conhecer.org.br/enciclop/2011a/agrarias/produtividade\%20de \%20milho.pdf>

PACCOLA-MEIRELLES, L. D; FERREIRA, A.S; MEIRELLES, W. F.; MARRIEL, I.E; CASELA, C.R. Detection of bacterium associated with a leaf spot disease of maize in Brazil. Journal of Phytopathology, v. 149, p. 275-279, 2001. Disponível em: https://doi.org/10.1046/j.1439-0434.2001.00614.x. DOI: 10.1046/j.14390434.2001.00614.x

PEREIRA, O. A. P.; DE CARVALho, R. V.; CAMARGo, L. E. A. Doenças do Milho. In: KIMATI, H.; AMORIM, L.; REZENDE, J. A. M.; BERGAMIN FILHO, A.; CAMARGO, L. E. A. Manual de Fitopatologia: Doenças das plantas cultivadas. 4ed. São Paulo: Agronômica Ceres, 2005. p. 477-488. 
RAMATHANI, I.; BIRUMA, M.; MARTIN, T.; DIXELIUS, C.; OKORI, P. Disease severity, incidence and races of Setosphaeria turcica on sorghum in Uganda. European Journal of Plant Pathology, v. 131, p. 383-392, 2011. Disponível em: < https://link.springer.com/article/10.1007/s10658-011-9815-1>. DOI 10.1007/s10658011-9815-1

REZENDE, P.; SILVA, C. R.; RUFFATO, S.; BONALDO, S. M. Fungicidas em milho segunda safra: controle de cercosporiose e helmintosporiose, produtividade, retorno econômico e qualidade de grãos. Scientific Electronic Archives, v. 10, n.5, 2017. Disponível em: <http://www.seasinop.com.br/revista/index.php? journal=SEA\&page=article\&op=view\&path $\% 5 B \% 5 D=388 \&$ path $\% 5 B \% 5 D=p d f$.

ROSA, W. B.; DUARTE, J. B. J; QUEIROZ, S B; PEREGO, I.; MATTEI, E. Desempenho agronômico de cinco híbridos de milho submetidos à aplicação de fungicida em diferentes estádios fenológicos. Revista Engenharia na Agricultura, v. $25, \quad$ n. $5, \quad$ p. 428-435, 2017. Disponível em:< http://www.seer.ufv.br/seer/index.php/reveng>

SILVA A. G.; FRANCISCHINI, R.; TEIXEIRA, R. I.; GOULART, M. M. P. Aplicação de fungicida em híbridos de milho na safra de verão na região Central do Brasil, Magistra, V. 28, N.3/4, p.379-389, 2016. Disponível em:< https://magistraonline.ufrb.edu.br/index.php/magistra/article/view/300/290>.

UEBEL, J. D. Avaliação de fungicidas no controle de doenças foliares, grãos ardidos e efeito no NDVI (Índice de Vegetação por Diferença Normalizada) em híbridos de milho. 2015. 119 f., il. Dissertação (Mestrado em Agronomia), Universidade de Brasília, Brasília, 2015.

VILELA, R. G.; ARF, O.; KAPPES, C. KANEKO, F. H. GITTI, D. C.; FERREIRA, J. P. Desempenho agronômico de híbridos de milho, em função da aplicação foliar de fungicidas. Bioscience Journal, v. 28, n. 1, p. 25-33, 2012. Disponível em: <http://rbms.cnpms.embrapa.br/index.php/ojs/article/view/358>. 